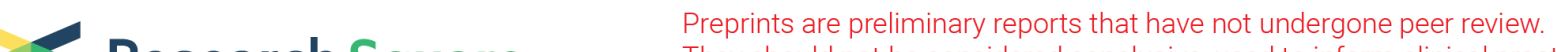 $\begin{array}{ll}\text { Research Square } & \text { They should not be considered conclusive, used to inform clinical practice, } \\ \text { or referenced by the media as validated information. }\end{array}$
}

\section{Comparison of Serum Progesterone Levels of the Day of Frozen Embryo Transfers According to Type of Endometrial Preparation: A Monocentric, Retrospective Study}

Olivier Pouget ( $\nabla$ pouget@abcgyneco.fr)

CHU Nimes https://orcid.org/0000-0003-1865-5542 Irma Zuna

CHU Nimes: Centre Hospitalier Universitaire de Nimes

Marine Bonneau

CHU Nimes: Centre Hospitalier Universitaire de Nimes

Marie Laure Tailland

CHU Nimes: Centre Hospitalier Universitaire de Nimes

\section{Sylvie Neveu-Ripart}

CHU Nimes: Centre Hospitalier Universitaire de Nimes

\section{Nathalie Rougier-Maillard}

CHU Nimes: Centre Hospitalier Universitaire de Nimes

\section{Sophie Poirey}

CHU Nimes: Centre Hospitalier Universitaire de Nimes

\section{Stéphanie Huberlant}

CHU Nimes: Centre Hospitalier Universitaire de Nimes

\section{Research article}

Keywords: Frozen embryo transfer, serum progesterone, clinical pregnancy with foetal heartbeat rate, hormone replacement therapy, artificial cycle, natural cycle, endometrial preparation

Posted Date: October 29th, 2020

DOI: https://doi.org/10.21203/rs.3.rs-97769/v1

License: (9) (1) This work is licensed under a Creative Commons Attribution 4.0 International License. Read Full License 


\section{Abstract}

Background: Live birth rate following embryo transfer is comparable between natural cycle and hormonal therapy. However, pregnancy loss rate appears elevated with hormonal therapy, possibly due to luteal insufficiency, characterised by a low level of serum progesterone in the luteal phase. The primary objective of this study, was to determine whether serum progesterone level on transfer day differed according to endometrial preparation method in patients undergoing frozen embryo transfer (FET). Secondary objectives were to compare the clinical pregnancy with foetal heartbeat rate and pregnancy loss rate according to endometrial preparation method and to compare the level of serum progesterone on the transfer day between pregnancy loss and pregnancy with foetal heartbeat.

Methods: Forty-seven natural/stimulated cycles and 68 artificial cycle FET were retrospectively studied from May to December 2019 from a single French hospital. The primary endpoint was the level of serum progesterone on the day of FET. The type of infertility, aetiology, serum basal FSH, LH, oestradiol and $\mathrm{AMH}$ dosage, endometrial thickness, clinical pregnancy rate, pregnancy loss rate, and maternal and embryo characteristics were compared between natural/stimulated cycle (OS group) and artificial cycle (AC group).

Results: Mean serum progesterone level on embryo transfer day was $25.47 \mathrm{ng} / \mathrm{mL}$ in the OS group versus $14.32 \mathrm{ng} / \mathrm{mL}$ AC group $(\mathrm{p}<0.0001)$. There was no significant difference in demographic and hormone characteristics (age, type of embryo, type of infertility, basal FSH, LH, oestradiol and AMH levels), endometrial thickness, number and type of embryos transferred, duration of infertility, pregnancy rate and pregnancy loss rate. Body mass index was lower in the OS group than AC group ( $22.9 \mathrm{~kg} / \mathrm{m} 2$ vs 24.8 $\mathrm{kg} / \mathrm{m} 2, \mathrm{p}=0.03$ ). No difference was found in serum progesterone level between clinical pregnancy with foetal heartbeat and pregnancy loss (respectively $17.48 \mathrm{ng} / \mathrm{mL}$ vs $20.82 \mathrm{ng} / \mathrm{mL}, p=0.7$ and 22 ongoing pregnancies and 12 pregnancy loss).

Conclusions: Serum progesterone level on FET day is lower with endometrial preparation with artificial cycle than with a natural/stimulated cycle. Further research is necessary to determine if this difference has any relation with higher pregnancy loss rate with artificial cycle.

\section{Background}

Frozen embryo transfers (FET) are increasingly common ${ }^{1}$, in part due to modification of clinical protocols that favour freezing in patients at a high risk of hyperstimulation, but also due to improvements in biological techniques like cryopreservation and oocyte vitrification. The endometrium must be prepared to allow successful transferred embryo implantation via various endometrial preparation protocols. In a natural cycle, endometrial preparation with or without ovulation induction using Follicle Stimulating Hormone (FSH) triggers the development of a main follicle, producing a corpus luteum that secretes progesterone in the luteal phase and can be sustained with exogenous progesterone ${ }^{2}$. This method requires regular monitoring. In an artificial cycle (AC), the endometrium is prepared by oral or transdermal 
oestradiol to stimulate the growth of the endometrium, whilst blocking the patient's gonadotropic pathway, and administering progesterone in the luteal phase to differentiate the endometrium. This method has the advantage of being easier to monitor and manage. The choice of protocol depends on several factors, such as the existence or not of an ovulatory cycle, presence of endometriosis and adenomyosis, and the patient's tolerance of the treatment (injections, patches, vaginal suppositories).

There is no current consensus on which type of preparation is best. The implantation rates per embryo are comparable between the endometrial preparation methods ${ }^{3}$. However, results on the rate of miscarriages with substituted cycles are contradictory ${ }^{4-6}$, and there is no apparent difference in the rate of ongoing pregnancies or birth rate according to cycle type ${ }^{7}$. Some research teams have shown that AC results in fewer clinical pregnancies when the progesterone level on the day of the FET is lower, especially below a threshold of $9.2 \mathrm{ng} / \mathrm{mL}^{8,9}$. Another team recently proposed a higher progesterone threshold of $20.6 \mathrm{ng} / \mathrm{mL}^{10}$. Other studies have demonstrated that the chances of clinical pregnancy were higher if the progesterone level on Day 10 of the transfer was above $35 \mathrm{nmol} / \mathrm{L}^{11}$, if the progesterone level on Day 16 of the embryo transfer was over $50 \mathrm{nmol} / \mathrm{mL}^{12}$, or if the progesterone level in the middle of the luteal phase was over $7.9 \mathrm{ng} / \mathrm{mL}^{13}$. Currently, there is no consensus on when to measure progesterone or the optimum threshold.

The primary objective of our study was to compare the progesterone level on the day of transfer depending on the endometrial preparation protocol (spontaneous or substituted cycle) used. Secondary objectives were to characterise normal progesterone levels depending on the day of the embryo transfer, to observe the rate of pregnancies and pregnancy loss depending on the preparation protocol, and to determine the progesterone level threshold for clinical pregnancies.

\section{Methods}

\section{Study design and participants}

This was a retrospective observational study on data from patients having undergone FET cycle at Nimes university hospital from May 2019 to December 2019. Medical and sociodemographic data were collected using medical JFIV ${ }^{\circledR}$ software, registered with the French data protection authority (CNIL) in accordance with law on national data protection and civil liberties (No. $78-17$ dated January 6th, 1978). The study was approved by the Institutional Review Board at Nimes University Hospital, France (IRB $n^{\circ}$ 20.02.01). Patients had all previously agreed to the use of their data in future research. All patients who had undergone a FET and who did not respond to the non-opposition letter were studied. Patients without a progesterone level test on the day of the transfer were excluded from the study.

\section{Endometrial preparation protocols}

Patients were grouped according to endometrial preparation protocol. Patients in the mild ovarian stimulation or natural cycle (OS group) underwent endometrial preparation during spontaneous or 
stimulated cycle (FSH or human menopausal gonadotropin (hMG), starting dose ranging from $37.5 \mathrm{IU}$ to $75 \mathrm{IU}$ initiated between the 3rd and 7th day of the cycle), with the presence of a dominant follicle and a corpus luteum. Ovulation was triggered by recombinant human chorionic gonadotropin (hCG) $(250 \mu \mathrm{g}$ Ovitrelle, Merck Serono), with a stimulated or spontaneous cycle, according to clinician preference. The luteal phase was sustained with $600 \mathrm{mg} /$ day of micronised progesterone (Progestan ${ }^{\circledR}$ Besins International, France) for up to nine weeks.

Patients in the artificial cycle (AC) group underwent a hormonal therapy cycle, with endometrial preparation with oestrogen given orally (Ethinyl Estradiol $6 \mathrm{mg}$ per day, PROVAMES ${ }^{\circledR}, \mathrm{SERB}$, France) or transdermally (VIVELLEDOT ${ }^{\circledR} 150 \mu \mathrm{g}$ oestradiol patch, SANDOZ laboratories France, one patch changed every two days), preceded or not by desensitisation via a gonadotrophin-releasing hormone (GnRH) agonist injection (Triptoreline 3 mg (DECAPEPTYL, Ipsen Pharma, Boulogne Billancourt, France) 15 days prior to oestradiol). The luteal phase was sustained with oestradiol and with $800 \mathrm{mg} /$ day of micronised progesterone for up to 12 weeks.

Frozen embryos at the cleavage or blastocyst stage were transferred between Day 2 and Day 5. The embryos were frozen by vitrification (Vit kit- Freeze, Irvine Scientific ${ }^{\circledR}$, Paris, France) according to the manufacturer's procedure ${ }^{14}$. After thawing, each embryo was inspected to assess the number of cells present. Embryos were eligible for FET if more than $50 \%$ of the cells were intact on Day 2 or 3 . At the blastocyst stage, the embryo was eligible for transfer after thawing if less than $25 \%$ lysis was observed. The development stage and number of embryos transferred was determined on a case-by-case basis, up to a maximum of three embryos.

The primary outcome was the progesterone level $(\mathrm{ng} / \mathrm{mL})$ on the day of the embryo transfer. Samples were taken at 10 a.m. at the hospital's medically assisted procreation department laboratory. The demographic variables analysed were body mass index (BMI), the type (primary/secondary) and duration of infertility, cause of infertility (tubal, ovulatory, male factor, endometriosis), exposure to nicotine and the hormone levels on Day 3 (FSH, luteinizing hormone (LH), oestradiol and anti-Müllerian hormone (AMH).

The embryonic development stage was assessed at the time of transfer (early transfer on Day 2-3, cleavage or prolonged culture with transfer on Day 4-6), the number of embryos transferred, their age at the time of freezing and thawing, the thickness of the endometrium before progesterone treatment, and the levels of LH and oestradiol on the day of transfer (sampled at 10 a.m.) were also recorded.

Positive pregnancy was considered for patients with a positive hCG blood test (superior to $100 \mathrm{UI} / \mathrm{dL}$ ). Progressive pregnancy with a heartbeat activity at seven weeks by ultrasound scan was classed as "clinical pregnancy with foetal heartbeat". A pregnancy documented by a positive human chorionic gonadotrophin without foetal heartbeat at 7 week of gestational age was classed as "pregnancy loss".

We correlated the serum progesterone level at the end of the FET cycle in terms of pregnancy rate per cycle, the rate of pregnancy loss per pregnancy and the rate of clinical pregnancies with foetal heartbeat per cycle ${ }^{15}$. 


\section{Data sources/ measurements}

Progesterone, LH and oestradiol levels were analysed at the biochemistry laboratory at Nîmes University Hospital via electrochemiluminescence (ECLIA) with Elecsys Progesterone III, Elecsys LH and Elecsys Estroadiol III, respectively, performed on a Cobas e801 (Roche Diagnostics) analyser. The Day 3 hormone tests (FSH, LH, Estradiol and AMH) were either performed in our laboratory or a community laboratory. Endometrial thickness was measured by one of two trained operators using an S10 ultrasound machine (Voluson, GE Healthcare) and a transvaginal probe.

\section{Bias}

To reduce the risk of inclusion bias, we included all patients with known progesterone level during the inclusion period. As serum progesterone levels may vary according to treatment received or because of difference between groups (patients with ovulatory infertility are more likely to receive substituted treatment ${ }^{16,17}$ ), we performed a sub-group analysis excluding ovulatory infertility patients.

\section{Sample size}

Based on a previous study in which women received $200 \mathrm{mg}$ vaginally-administered progesterone twice a day (versus three times per day here), we estimated that the Cmax progesterone level with a substituted cycle would be $13 \pm 4 \mathrm{ng} / \mathrm{ml}^{18}$. The average progesterone level at the middle of the luteal phase with a spontaneous cycle would be expected to be $19.4 \pm 6.4 \mathrm{ng} / \mathrm{mL}^{19}$. Thus, the number of subjects necessary to observe a difference of $6 \mathrm{ng} / \mathrm{mL}$ with an alpha risk of $5 \%$ and a power of $90 \%$ in a unilateral test was 19 subjects in each group.

\section{Statistical methods}

Quantitative data were compared with a Mann-Whitney-Wilcoxon test and qualitative variables with Fisher's exact test. Calculations were performed using the $R \circledast$ statistical software (Version 3.6.1, Foundation for Statistical Computing, Vienna, Austria). Differences between groups are given as Odds Ratio (OR) with $95 \%$ confidence interval $(95 \% \mathrm{Cl})$. If a variable was missing for the primary outcome, the patient was not included in the study. If a variable was missing for a secondary criterion, the patient was excluded from the analysis. A p-value $<0.05$ was considered to be statistically significant.

A receiver operating characteristic $(\mathrm{ROC})$ curve was constructed to determine a global threshold value for a serum progesterone level for clinical pregnancy with foetal heartbeat, based on the total population.

\section{Results}

\section{Participants}

During the inclusion period, 211 patients underwent FET in our department, of whom 117 underwent an artificial cycle preparation (AC) and 94 a natural or stimulated cycle (OS). Fifty patients in the AC group 
and 47 in the OS group were excluded as they did not have progesterone concentration levels measured on the day of transfer. Thus, 67 patients were eligible for inclusion in the AC group and 47 in the OS group. LH and oestradiol concentration on the day of transfer was missing for 19 patients in the OS group and 27 patients in the AC group. Patient characteristics in the two groups are summarised in Table 1.

Table 1

Baseline patient characteristics

\begin{tabular}{|c|c|c|c|}
\hline & OS Group $(n=47)$ & AC Group $(n=67)$ & $\mathrm{p}$ \\
\hline Early embryo transfers (Day $1-3$ ) & $14(29.8 \%)$ & $31(46.3 \%)$ & 0.11 \\
\hline Blastocyst transfers (Day 4-6) & $33(70.2 \%)$ & $36(53.7 \%)$ & \\
\hline Patient age at the time of freezing (years) & $32.3(22.9-42.1)$ & $32.5(23.1-42.4)$ & 0.88 \\
\hline Patient age at the time of transfer (years) & $33.1(23.1-42.3)$ & $33.4(24.7-46.3)$ & 0.92 \\
\hline Body Mass Index (kg/m2) & $22.87(17-35)$ & $24.82(18-37)$ & 0.03 \\
\hline
\end{tabular}

No difference can be seen between the two groups concerning the number of embryos transferred early or at the blastocyst stage, and there was no significant difference in the age of patients at the time of freezing the embryos or at the time of transfer. In contrast, patients in the AC group had a significantly higher BMI (24.82 vs $22.87 \mathrm{~kg} / \mathrm{m} 2 . \mathrm{p}=0.03)$.

The type of infertility, causes of infertility, the baseline ovarian stock, the number of embryos transferred and the endometrial measurement at the end of the follicular phase (the day of LH surge or injection of HCG in OS group, or prior to initiating progesterone treatment in AC group) are presented in Table 2. 
Table 2

Population characteristics

\begin{tabular}{|c|c|c|c|c|}
\hline & $\begin{array}{l}\text { OS Group } \\
(n=47)\end{array}$ & $\begin{array}{l}\text { AC Group } \\
(n=67)\end{array}$ & OR $(95 \% \mathrm{Cl})$ & p \\
\hline Patients with secondary infertility & $13(27.66 \%)$ & $21(31.34 \%)$ & $\begin{array}{l}0.86(0.34- \\
2.09)^{(0)}\end{array}$ & 0.84 \\
\hline Duration of infertility (years) (+/-SD) & $\begin{array}{l}4.13(+/- \\
2.39)\end{array}$ & $\begin{array}{l}4.57(+/- \\
2.57)\end{array}$ & & 0.22 \\
\hline \multicolumn{5}{|l|}{ Type of infertility } \\
\hline o Tubal & $17(36 \%)$ & $19(28 \%)$ & $\begin{array}{l}1.35(0.57- \\
3.22)\end{array}$ & 1 \\
\hline o Ovulatory & $7(15 \%)$ & $22(33 \%)$ & $\begin{array}{l}0.35(0.11- \\
0.94)\end{array}$ & 0.03 \\
\hline o Male & $16(34 \%)$ & $22(33 \%)$ & $\begin{array}{l}1.01(0.42- \\
2.37)\end{array}$ & 1 \\
\hline o Endometriosis & $3(6 \%)$ & $8(12 \%)$ & $\begin{array}{l}0.51(0.08- \\
2.30)\end{array}$ & 0.52 \\
\hline Smoking & $10(21 \%)$ & $15(22 \%)$ & $\begin{array}{l}0.95(0.34- \\
2.57)\end{array}$ & 1 \\
\hline FSH (IU/L) on Day 3 (+/-SD) & $\begin{array}{l}6.50(+/- \\
1.72)\end{array}$ & $\begin{array}{l}6.69(+/- \\
2.18)\end{array}$ & & 1 \\
\hline LH (IU/L) on Day $3(+/-S D) *$ & $\begin{array}{l}6.73(+/- \\
2.81)\end{array}$ & $\begin{array}{l}7.94(+/- \\
4.24)\end{array}$ & & 0.27 \\
\hline Oestradiol $(\mathrm{ng} / \mathrm{mL})$ on Day $3(+/-\mathrm{SD})$ * & $\begin{array}{l}58.83(+/- \\
53.82)\end{array}$ & $\begin{array}{l}49.86(+/- \\
25)\end{array}$ & & 0.42 \\
\hline $\mathrm{AMH}(\mathrm{ng} / \mathrm{mL})(+/-\mathrm{SD})$ & $\begin{array}{l}3.92(+/- \\
3.27)\end{array}$ & $\begin{array}{l}5.00(+/- \\
4.14)\end{array}$ & & 0.18 \\
\hline $\begin{array}{l}\text { Endometrial thickness (before starting } \\
\text { progesterone) }(\mathrm{mm})(+/-\mathrm{SD})\end{array}$ & $\begin{array}{l}8.94(+/- \\
1.38)\end{array}$ & $\begin{array}{l}8.83(+/- \\
2.01)\end{array}$ & & 0.72 \\
\hline Number of embryos transferred (+/-SD) & $\begin{array}{l}1.34(+/- \\
0.47)\end{array}$ & $\begin{array}{l}1.36(+/- \\
0.57)\end{array}$ & & 0.77 \\
\hline
\end{tabular}

More patients in the AC group had ovulatory infertility (33\% vs $15 \%, p=0.03)$. In contrast, the type of infertility, duration of infertility and the baseline hormone levels, thickness of the endometrium and the number of embryos transferred were not different between groups.

\section{Primary outcome: progesterone level on the day of transfer according to endometrial preparation protocol}


Table 3

Hormone levels on day of transfer and pregnancy outcomes

\begin{tabular}{|c|c|c|c|c|}
\hline & $\begin{array}{l}\text { OS Group } \\
(\mathrm{n}=47)\end{array}$ & $\begin{array}{l}\text { AC Group } \\
(n=67)\end{array}$ & $\begin{array}{l}\mathrm{OR}(95 \% \\
\mathrm{Cl})\end{array}$ & p \\
\hline Progesterone $(\mathrm{ng} / \mathrm{mL})(+/-\mathrm{DS})$ & $\begin{array}{l}25.47(+/- \\
11.9)\end{array}$ & $\begin{array}{l}14.32(+/- \\
11.45)\end{array}$ & & $\dot{0}_{0.00001}$ \\
\hline Oestradiol (ng/mL) (+/- DS) & $\begin{array}{l}143.16(+/- \\
76.3)\end{array}$ & $\begin{array}{l}329.52(+/- \\
310.8)\end{array}$ & & 0.00008 \\
\hline $\mathrm{LH}(\mathrm{IU} / \mathrm{mL})(+/-\mathrm{DS})$ & $\begin{array}{l}6.31(+/- \\
3.96)\end{array}$ & $\begin{array}{l}2.89 \\
(+/-1.93)\end{array}$ & & 0.002 \\
\hline Pregnancy rate per cycle (number) & $29.7 \%(14)$ & $29.8 \%(20)$ & $\begin{array}{l}0.95 \\
(0.38- \\
2.29)\end{array}$ & 1 \\
\hline $\begin{array}{l}\text { Rate of pregnancy loss / pregnancies } \\
\text { (number) }\end{array}$ & $21 \%(3)$ & $43 \%(9)$ & $\begin{array}{l}0.45 \\
(0.07- \\
1.94)\end{array}$ & 0.35 \\
\hline $\begin{array}{l}\text { Rate of clinical pregnancy with foetal } \\
\text { heartbeat / cycle (number) }\end{array}$ & $23.4 \%(11)$ & $16.4 \%(11)$ & $\begin{array}{l}1.55 \\
(0.55- \\
4.41)\end{array}$ & 0.47 \\
\hline
\end{tabular}

Serum progesterone and LH levels on the day of transfer were significantly higher in the OS group (14.32 vs $25.47, p<0.0001$ and 2.89 vs $6.31, p=0.002$, respectively), whilst oestradiol was significantly lower (329.52 vs 143.16, $p=0.00008$ ) (Fig. 1, Table 3).

To limit the risk of a bias related to different populations in the two groups, we performed an analysis excluding patients with ovulatory infertility ( $n=40$ OS group versus $n=45$ cycles AC group). The progesterone level was significantly different between groups with $25.9 \mathrm{ng} / \mathrm{mL}$ for the OS group versus $15.5 \mathrm{ng} / \mathrm{mL}$ for the AC group ( $\mathrm{p}<0.00001)$. After excluding ovulatory infertility patients, no significant or clinical difference could be found in the AMH levels between the groups ( $3.3 \mathrm{vs} 3.6 \mathrm{ng} / \mathrm{mL}, \mathrm{p}=0.59$ ).

\section{Secondary Outcomes}

A large variability was observed in average serum progesterone level on the day of transfer, depending on the day of the transfer (Fig. 2).

We observed no between-group difference in rates of pregnancy (29.7\% OS versus $29.8 \% A C, p=1)$, pregnancy loss $(21 \%$ OS versus $43 \% A C, p=0.35)$ or clinical pregnancy with foetal heartbeat $(23.4 \%$ OS versus $16.4 \% A C, p=0.47$ ) (Table 3 ). In all patients, no significant difference was found in progesterone levels on the day of transfer between patients with clinical pregnancy with foetal heartbeat versus those who experienced pregnancy loss $(17.49 \mathrm{ng} / \mathrm{mL}$ for clinical pregnancy with foetal heartbeat vs $20.83 \mathrm{ng} / \mathrm{mL}$ for pregnancy loss, $\mathrm{p}=0.7)$.

The area under the curve (AUC) of the ROC curve for global serum progesterone level to predict clinical pregnancy with foetal heartbeat is 0.48 (Fig. 3). Therefore, in our population, there is no threshold value 
for progesterone for clinical pregnancy with foetal heartbeat.

The ROC curve of the AC group showed an AUC of 0.5, also failing to give a cut-off progesterone level for clinical pregnancy with foetal heartbeat.

\section{Discussion}

\section{Key results}

Our study shows a significant difference in the level of serum progesterone depending on the type of endometrial preparation. Endometrial preparations during a naturel or stimulated cycle, with a corpus luteum secreting progesterone, result in higher serum progesterone levels. This luteal insufficiency observed with endometrial preparations with a substituted cycle, without a corpus luteum, marked by lower progesterone levels on the day of transfer, might partly explain the higher rate of pregnancy loss observed in these patients in certain studies. However, we observed no difference in the rate of pregnancy loss.

Increasing the doses of vaginal progesterone given does not noticeably increase the serum progesterone level; indeed, it is the method of application that affects serum progesterone level, with intramuscular application subcutaneous progesterone providing a greater impact ${ }^{18}$. Preliminary data suggest that when progesterone level is less than $9 \mathrm{ng} / \mathrm{mL}$ on the day of transfer, addition of Progiron ${ }^{\circledR}$ subcutaneous progesterone can achieve a clinical pregnancy rate comparable to the rate observed in patients with a normal level of serum progesterone on the day of transfer ${ }^{20}$.

Dydrogesterone could also be added orally in the luteal phase. Oral dydrogesterone has been shown to be non-inferior compared with vaginally-applied micronised progesterone in in-vitro fertilisation using fresh embryos ${ }^{21}$. However, there is currently no data to support the efficacy of dydrogesterone in FETs. Furthermore, application of dydrogesterone does not increase serum progesterone levels, as it is not easy to measure in routine care. It is therefore difficult to monitor and confirm its value in the luteal phase.

While most studies show no difference in birth rate irrespective of the endometrial preparation protocol, they are mainly retrospective studies or studies with small numbers pooling ovulating and anovulating patients. One recent study showed a benefit on birth rate with a spontaneous cycle versus artificial cycle in patients who do not have ovulatory infertility ${ }^{22}$. Finally, the absence of corpus luteum in protocols with substituted cycles could lead to a risk of obstetric complications, especially pre-eclampsia ${ }^{23}$, postpartum haemorrhage, and caesarean Sect. ${ }^{24}$.

\section{Limitations}

The limitation of our study was that the sample size was too small to detect a difference in the rate of clinical pregnancy depending on the protocol, and that the long-term outcomes (live birth rate) were not analysed. 


\section{Conclusions}

In conclusion, the serum progesterone level on the day of transfer is significantly lower for a substituted cycle preparation compared with a spontaneous or stimulated cycle preparation in FET. Further studies are required to evaluate the impact of a lower progesterone level in the luteal phase at the time of FET and to evaluate whether a modification in the protocol with a substituted cycle could correct the progesterone level in the luteal phase.

\section{Abbreviations}

AC: artificial cycle; AMH: anti-Müllerian hormone; BMI: Body Mass Index; Cl: confidence interval; FET: frozen embryo transfers; FSH: follicle stimulating hormone; LH: luteinizing hormone; OS: ovarian stimulation; ROC: receiver operating characteristic

\section{Declarations}

\section{Ethics approval and consent to participate}

The study was approved by the Institutional Review Board at Nimes University Hospital, France (IRB $n^{\circ}$ 20.02.01). Patients had all previously agreed to the use of their data in future research. Patients were contacted by non-opposition letter and included if they did not oppose inclusion of their data.

\section{Consent for publication}

Not applicable.

\section{Availability of data and materials}

The datasets used and/or analysed during the current study are available from the corresponding author on reasonable request.

\section{Competing interests}

The authors declare that they have no competing interests.

\section{Funding}

This research did not receive any specific grant from funding agencies in the public, commercial, or notfor-profit sectors. 


\section{Authors' contributions}

OP conceived the study, analysed and interpreted data and wrote the first version of manuscript.

IZ, MB, MLT, SNR, NRM, SP, SH

All authors read and approved the final manuscript

\section{Acknowledgements}

We wish to thank Genevieve Pascal, midwife in our unit, Teresa Sawyers for translating the manuscript and Sarah Kabani for substantive editing.

\section{References}

1. De Geyter C, Calhaz-Jorge C, Kupka MS, et al. ART in Europe, 2014: results generated from European registries by ESHRE: The European IVF-monitoring Consortium (EIM) for the European Society of Human Reproduction and Embryology (ESHRE). Hum Reprod. 2018;33(9):1586-1601. doi:10.1093/humrep/dey242

2. Labrosse J, Lobersztajn A, Pietin-Vialle C, et al. Comparison of stimulated versus modified natural cycles for endometrial preparation prior to frozen embryo transfer: a randomized controlled trial. Reprod Biomed Online. 2020;40(4):518-524. doi:10.1016/j.rbmo.2020.01.007

3. Peeraer K, Couck I, Debrock S, et al. Frozen-thawed embryo transfer in a natural or mildly hormonally stimulated cycle in women with regular ovulatory cycles: a RCT. Hum Reprod. 2015;30(11):25522562. doi:10.1093/humrep/dev224

4. Mackens S, Santos-Ribeiro S, van de Vijver A, et al. Frozen embryo transfer: a review on the optimal endometrial preparation and timing. Hum Reprod. 2017;32(11):2234-2242. doi:10.1093/humrep/dex285

5. Tomás C, Alsbjerg B, Martikainen H, Humaidan P. Pregnancy loss after frozen-embryo transfer-a comparison of three protocols. Fertil Steril. 2012;98(5):1165-1169. doi:10.1016/j.fertnstert.2012.07.1058

6. Ghobara T, Gelbaya TA, Ayeleke RO. Cycle regimens for frozen-thawed embryo transfer. Cochrane Database Syst Rev. 2017;7:CD003414. doi:10.1002/14651858.CD003414.pub3

7. Peigné $M$, Devouche $E$, Ferraretto $X$, et al. Higher live birth rate with stimulated rather than artificial cycle for frozen-thawed embryo transfer. Eur J Obstet Gynecol Reprod Biol. 2019;243:144-149. doi:10.1016/j.ejogrb.2019.10.040

8. Cédrin-Durnerin I, Isnard T, Mahdjoub S, et al. Serum progesterone concentration and live birth rate in frozen-thawed embryo transfers with hormonally prepared endometrium. Reprod Biomed Online. 2019;38(3):472-480. doi:10.1016/j.rbmo.2018.11.026 
9. Labarta E, Mariani G, Holtmann N, Celada P, Remohí J, Bosch E. Low serum progesterone on the day of embryo transfer is associated with a diminished ongoing pregnancy rate in oocyte donation cycles after artificial endometrial preparation: a prospective study. Hum Reprod. 2017;32(12):24372442. doi:10.1093/humrep/dex316

10. Boynukalin FK, Gultomruk M, Turgut E, et al. Measuring the serum progesterone level on the day of transfer can be an additional tool to maximize ongoing pregnancies in single euploid frozen blastocyst transfers. Reprod Biol Endocrinol. 2019;17(1):102. doi:10.1186/s12958-019-0549-9

11. Alsbjerg B, Thomsen L, Elbaek HO, et al. Progesterone levels on pregnancy test day after hormone replacement therapy-cryopreserved embryo transfer cycles and related reproductive outcomes. Reprod Biomed Online. 2018;37(5):641-647. doi:10.1016/j.rbmo.2018.08.022

12. Basnayake SK, Volovsky M, Rombauts L, Osianlis T, Vollenhoven B, Healey M. Progesterone concentrations and dosage with frozen embryo transfers - What's best? Aust N Z J Obstet Gynaecol. 2018;58(5):533-538. doi:10.1111/ajo.12757

13. Arce J-C, Balen A, Platteau P, Pettersson G, Andersen AN. Mid-luteal progesterone concentrations are associated with live birth rates during ovulation induction. Reprod Biomed Online. 2011;22(5):449456. doi:10.1016/j.rbmo.2011.01.006

14. Wirleitner $B$, Vanderzwalmen $P$, Bach $M$, et al. The time aspect in storing vitrified blastocysts: its impact on survival rate, implantation potential and babies born. Hum Reprod. 2013;28(11):29502957. doi:10.1093/humrep/det361

15. Zegers-Hochschild F, Adamson GD, Dyer S, et al. The International Glossary on Infertility and Fertility Care, 2017. Fertil Steril. 2017;108(3):393-406. doi:10.1016/j.fertnstert.2017.06.005

16. Yu J, Ma Y, Wu Z, et al. Endometrial preparation protocol of the frozen-thawed embryo transfer in patients with polycystic ovary syndrome. Arch Gynecol Obstet. 2015;291(1):201-211. doi:10.1007/s00404-014-3396-0

17. Groenewoud ER, Cohlen BJ, Macklon NS. Programming the endometrium for deferred transfer of cryopreserved embryos: hormone replacement versus modified natural cycles. Fertil Steril. 2018;109(5):768-774. doi:10.1016/j.fertnstert.2018.02.135

18. Paulson RJ, Collins MG, Yankov VI. Progesterone pharmacokinetics and pharmacodynamics with 3 dosages and 2 regimens of an effervescent micronized progesterone vaginal insert. J Clin Endocrinol Metab. 2014;99(11):4241-4249. doi:10.1210/jc.2013-3937

19. Filicori M, Butler JP, Crowley WF. Neuroendocrine regulation of the corpus luteum in the human. Evidence for pulsatile progesterone secretion. J Clin Invest. 1984;73(6):1638-1647. doi:10.1172/JCI111370

20. Labarta E. A large prospective trial in unselected population confirms that low serum progesterone on the day of embryo transfer impairs pregnancy outcome in artificial cycles. Oral presentation 0173. 35th Annual ESHRE Meeting, 24-26 June, 2019.

21. Tournaye H, Sukhikh GT, Kahler E, Griesinger G. A Phase III randomized controlled trial comparing the efficacy, safety and tolerability of oral dydrogesterone versus micronized vaginal progesterone for 
luteal support in in vitro fertilization. Hum Reprod. 2017;32(5):1019-1027.

doi:10.1093/humrep/dex023

22. Singh B, Reschke L, Segars J, Baker VL. Frozen-thawed embryo transfer: the potential importance of the corpus luteum in preventing obstetrical complications. Fertility and Sterility. 2020;113(2):252257. doi:10.1016/j.fertnstert.2019.12.007

23. von Versen-Höynck F, Schaub AM, Chi Y-Y, et al. Increased Preeclampsia Risk and Reduced Aortic Compliance With In Vitro Fertilization Cycles in the Absence of a Corpus Luteum. Hypertension. 2019;73(3):640-649. doi:10.1161/HYPERTENSIONAHA.118.12043

24. Ginström Ernstad E, Wennerholm U-B, Khatibi A, Petzold M, Bergh C. Neonatal and maternal outcome after frozen embryo transfer: Increased risks in programmed cycles. Am J Obstet Gynecol. 2019;221(2):126.e1-126.e18. doi:10.1016/j.ajog.2019.03.010

\section{Figures}

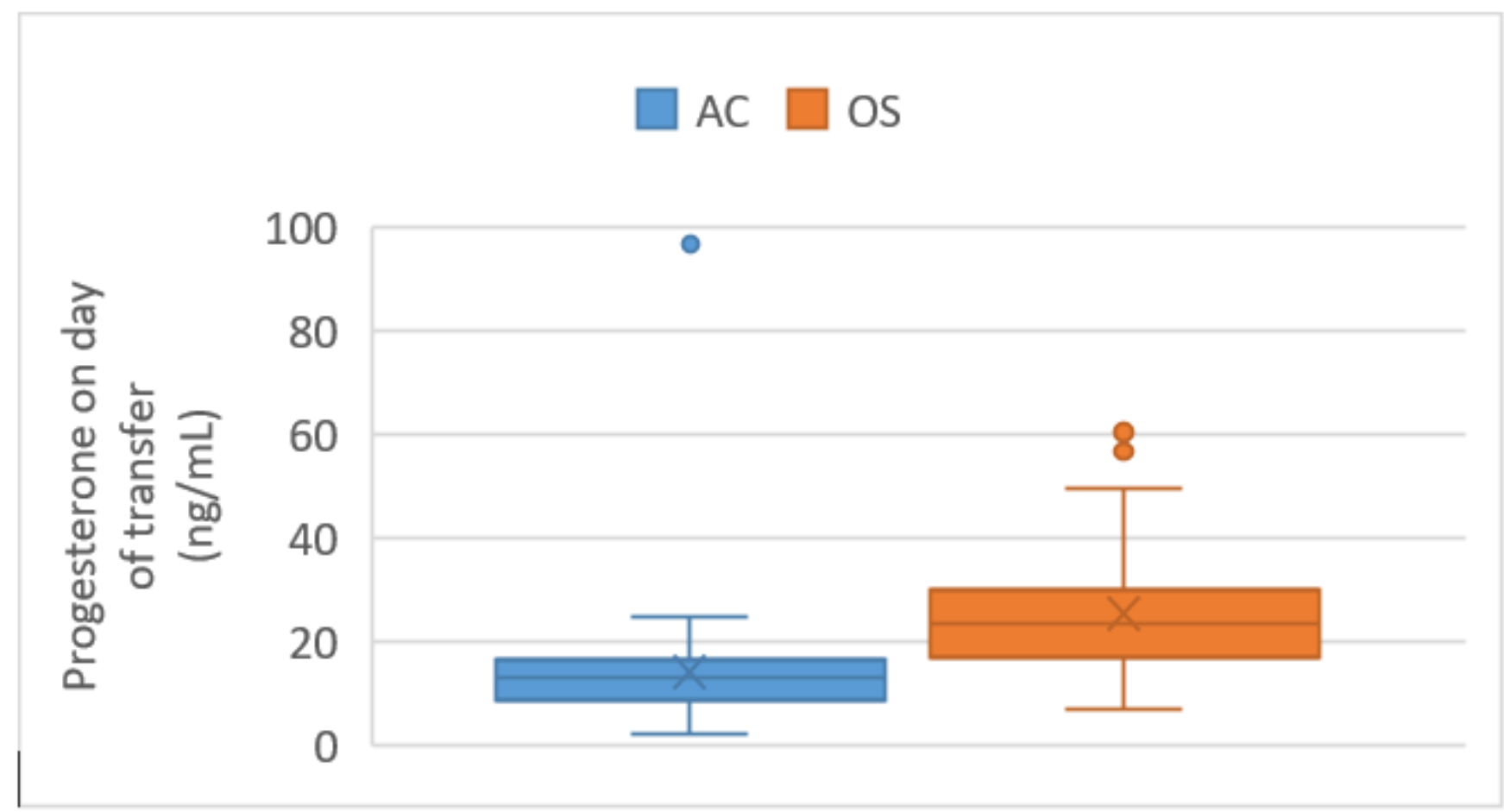

\section{Figure 1}

Box plots showing serum progesterone levels, where crosses denote the mean, horizontal lines denote median and boxes show the IQR. 


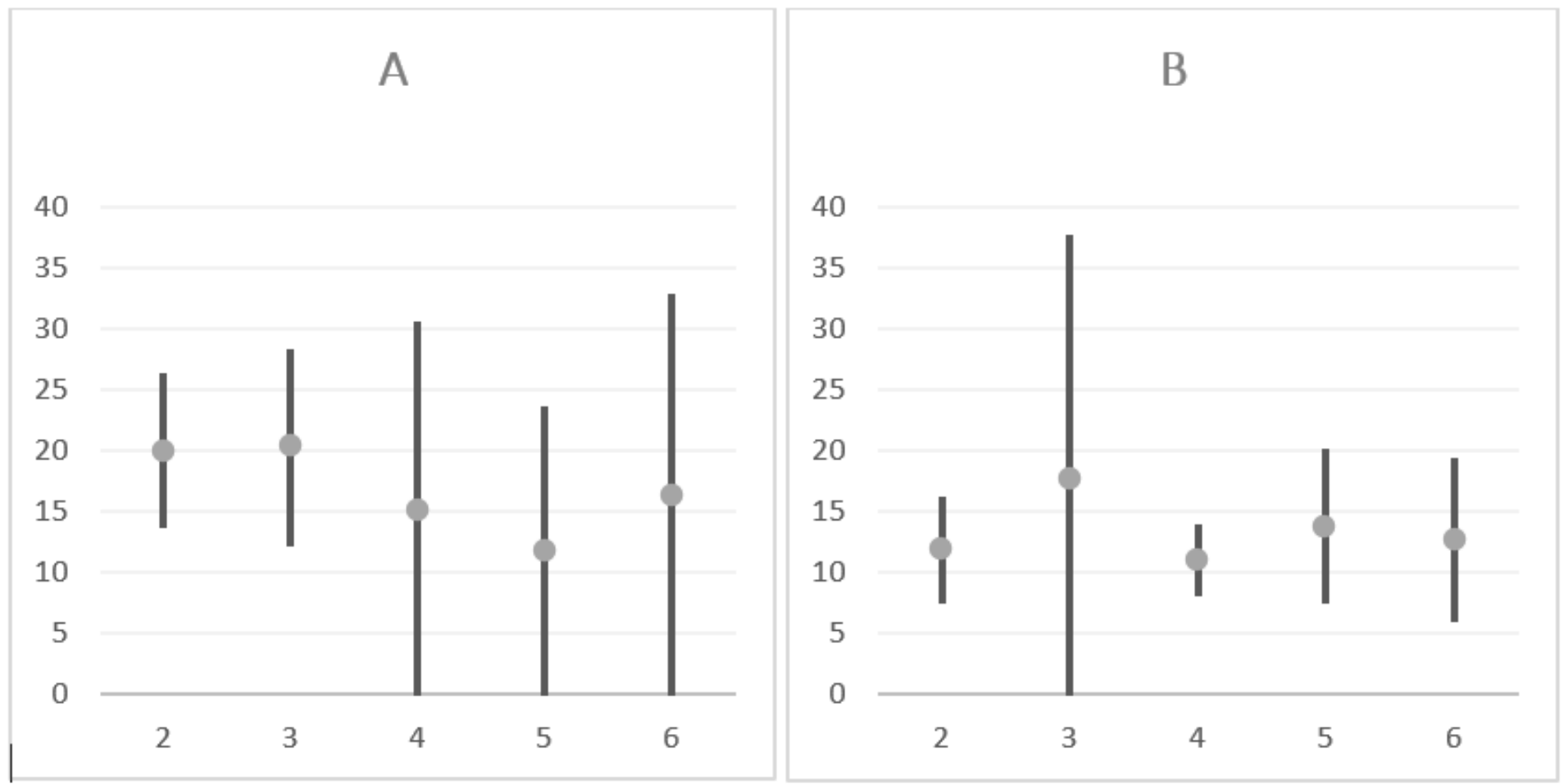

Figure 2

Mean serum progesterone level (in $\mathrm{ng} / \mathrm{mL}$ ) with standard deviation according to the day of progesterone supplementation in the luteal phase in A. AC group and B. OS group. 


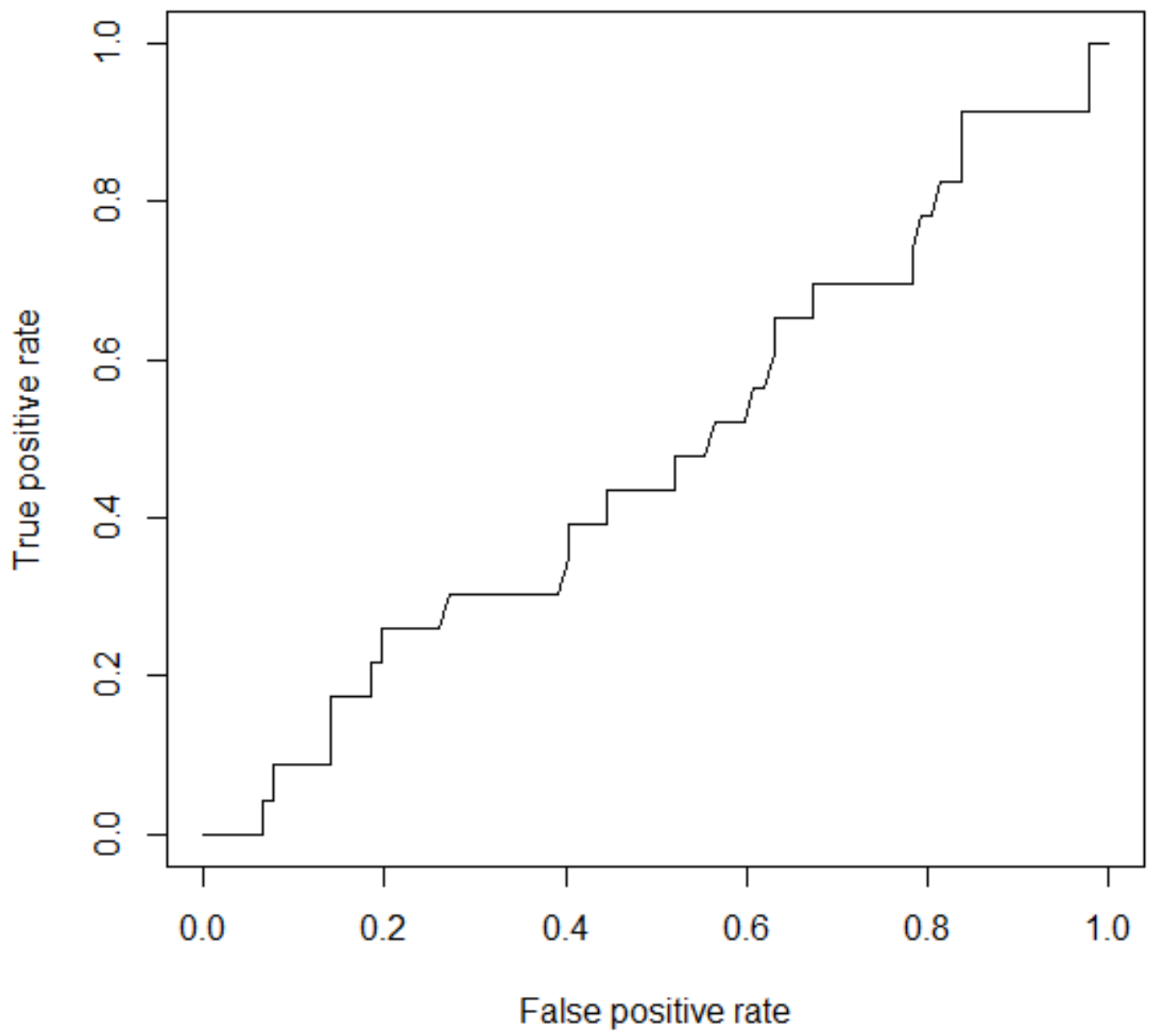

Figure 3

ROC of progesterone threshold for total population above which the clinical pregnancy with foetal heartbeat rate would be higher. 